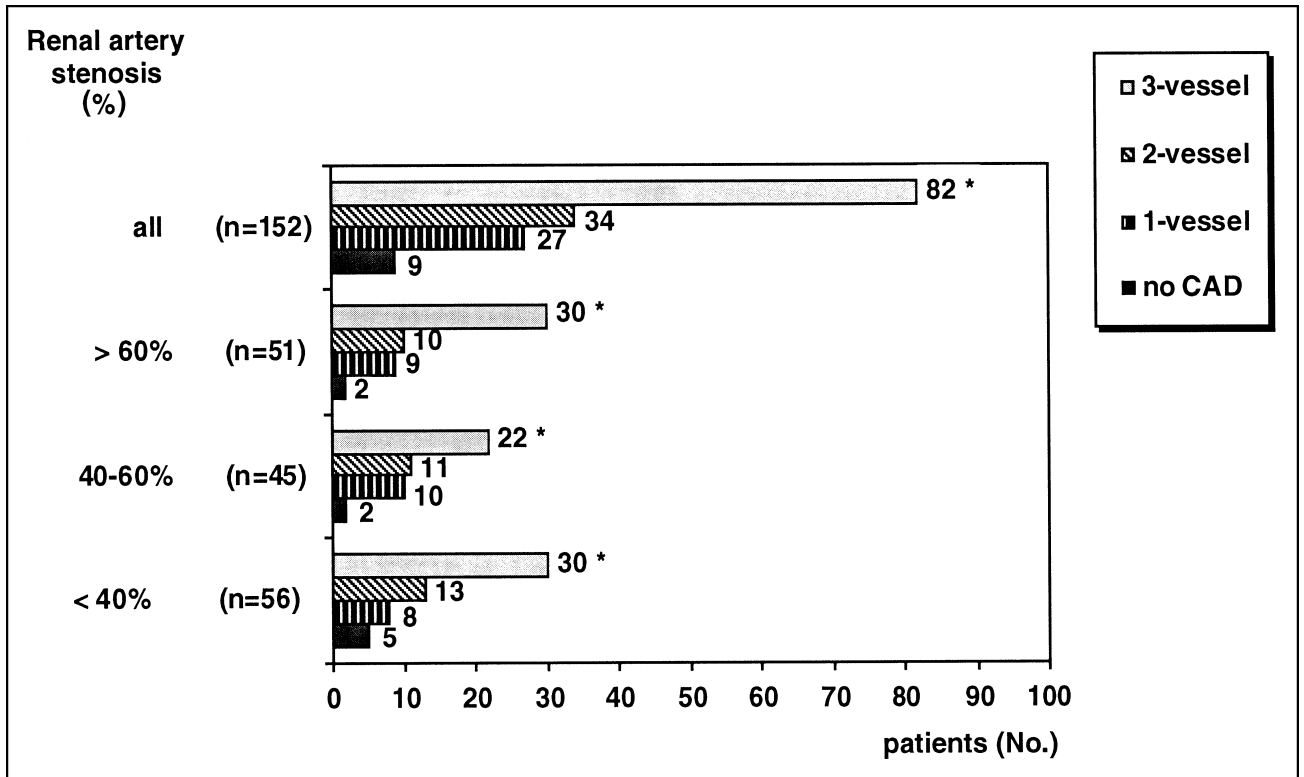

FIGURE 1. Ordinate shows patients with renal artery stenosis in terms of severity $(<40 \%, 40 \%$ to $60 \%$, $>60 \%)$. Abscissa shows numbers of patients. In each group, patients are separated in terms of severity of their CAD. Severity of CAD was equally distributed in each group and in the population as a whole. Three-vessel CAD was the most common (*p $<0.05)$.

coincidence of RAD and CAD, irrespective of RAD severity. Furthermore, the prevalence of no CAD in nonsignificant (5 patients), borderline (2 patients), and significant (2 patients) RAD was low.

These results would support the conclusion that the presence of atherosclerotic RAD warrants a search for CAD, to the point of coronary catheterization if clinically appropriate.

1. Valentine RJ, Clagett GP, Miller GL, Myers SI, Martin JD, Chervu A. The coronary risk of unsuspected renal artery stenosis. J Vasc Surg 1993;18:433-440.
2. Olin JW, Melia M, Young JR, Graor RA, Risius B. Prevalence of atherosclerotic renal artery stenosis in patients with atherosclerosis elsewhere. Am J Med 1990;88 (suppl 1N):46N-51N.

3. Louie J, Isaacson JA, Zierler RE, Bergelin RO, Strandness DE Jr. Prevalence of carotid and lower extremity arterial disease in patients with renal artery stenosis. Am J Hypertens 1994;7:436-439.

4. Rossi GP, Rossi A, Zanin L, Calabro A, Feltrin GP, Pessina AC, Crepaldi G, Dal-Palu C. Excess prevalence of extracranial carotid artery lesions in renovascular hypertension. Am J Hypertens 1992;5:8-15.

5. Harding MB, Smith LR, Himmelstein SI, Harrison K, Phillips HR, Schwab SJ, Hermiller JB, Davidson CJ, Bashore JM. Renal artery stenosis: prevalence and associated risk factors in patients. J Am Soc Nephrol 1992;2: $1608-1616$.

6. Jean WJ, Al-Bitar I, Zwicke DL, Port SC, Schmidt DH, Bajwa TK. High incidence of renal artery stenosis in patients with coronary artery disease. Cathet Cardiovasc Diagn 1994;32:8-10.

\title{
Predictive Accuracy of Echocardiographic Response of Mildly Dyssynergic Myocardial Segments to Low-Dose Dobutamine
}

\author{
Jan H. Cornel, MD, Jeroen J. Bax, MD, Abdou Elhendy, MD, Don Poldermans, MD, \\ Jean-Louis J. Vanoverschelde, MD, and Paolo M. Fioretti, MD
}

n patients with chronic coronary artery disease, resting contractile dysfunction may be caused by myocardial necrosis, hibernation, ${ }^{1}$ or repetitive stunning. ${ }^{2}$ Detection of contractile reserve during the infusion of low-dose dobutamine indicates that the seg-

From Department of Cardiology, Medical Center Alkmaar, Alkmaar; Department of Cardiology, University Hospital Leiden, Leiden, Thorax Center Rotterdam, Rotterdam, The Netherlands; Division of Cardiology, University of Louvain Medical School, Brussels, Belgium; and Istituto di Cardiologia, Udine, Italy. Dr. Bax's address is: Department of Cardiology, University Hospital Leiden, Rijnsburgerweg 10, 2333 AA Leiden, The Netherlands. Manuscript received April 22, 1997; revised manuscript received and accepted August 22, 1997 ment is viable and recovery of function may occur after coronary revascularization. ${ }^{3}$ Indeed, many studies have used low-dose dobutamine echocardiography to predict improvement of wall motion after revascularization and showed sensitivities ranging from $74 \%$ to $97 \%$ and specificities ranging from $69 \%$ to 96\%. ${ }^{4-11}$ Most studies focused on prediction of recovery of segments with severe wall motion abnormalities (severe hypokinesia, akinesia), because segments with mild hypokinesia are already considered viable independent of their response to dobutamine. However, the few available data showed that many hypokinetic segments exhibiting contractile reserve during dobut- 


\begin{tabular}{|cc|}
\hline TABLE I Baseline Characteristics of the Study Group \\
\hline Gender (M/F) & $73 / 18$ \\
Age (yr) & $60 \pm 9$ \\
Previous CABG & 10 \\
Previous myocardial infarction & \\
Q/non-Q wave & $65 / 26$ \\
Angina (NYHA class) & $2.3 \pm 0.7$ \\
Functional class & $1.6 \pm 0.8$ \\
Coronary arteriography & \\
l-vessel disease & 8 \\
2-vessel disease & 21 \\
3-vessel disease & 61 \\
LVEF (\%) & $31.7 \pm 11.1$ \\
Range (\%) & $13-35$ \\
\hline Numbers represent absolute numbers of patients. \\
CABG = coronary artery bypass grafting; LVEF = left ventricular angio- \\
graphic ejection fraction; NYHA = New York Heart Association. \\
\hline
\end{tabular}

amine did not improve in function after revascularization, resulting in a low specificity..$^{9,10}$ This is a particular important issue, since improvement of function after revascularization is associated with increased long-term survival. ${ }^{12}$ Therefore, we compared the sensitivity and specificity of low-dose dobutamine echocardiography to predict functional recovery in segments with severe wall motion abnormalities versus segments with mild wall motion abnormalities.

Consecutive patients $(\mathrm{n}=91)$ with chronic stable coronary artery disease and regional wall motion abnormalities on resting echocardiography were included in the study (Table I). The patients were already scheduled for revascularization (surgery in 85 and angioplasty in 7); the decision to revascularize was based only on clinical criteria. All patients underwent low-dose dobutamine echocardiography within 1 month of revascularization without intervening events. Beta blockers were withdrawn 36 hours before the test; all other cardiac medication was continued. A 2-dimensional echocardiogram (in standard apical and parasternal views) was recorded at rest. Dobutamine was infused intravenously at doses of 5 and $10 \mu \mathrm{g} /$ $\mathrm{kg} / \mathrm{min}$ ( 5 minutes at each dose). Continuous monitoring of the echocardiogram was obtained during the test and the images were recorded on videotape at the last minute of both stages. The images were also digitized (Vingmed CFM 800) and displayed in quadscreen format. The interpretation of echocardiograms was performed by 2 experienced observers blinded to clinical data. For analysis of echocardiograms we used a 16-segment model. Wall motion, including wall thickening, of each segment was scored on a 5-point scoring system: $1=$ normal, $2=$ mildly hypokinetic, $3=$ severely hypokinetic, $4=$ akinetic, and $5=$ dyskinetic. Wall thickening was primarily utilized for the classification of wall motion, preempting the problem of postoperative paradoxical septal motion. Additionally, in order to reduce the confounding effects of tethering, segmental wall thickening was analyzed frame by frame during the first half of systole.

Myocardial viability was judged present in a dyssynergic segment when wall motion during the infu-

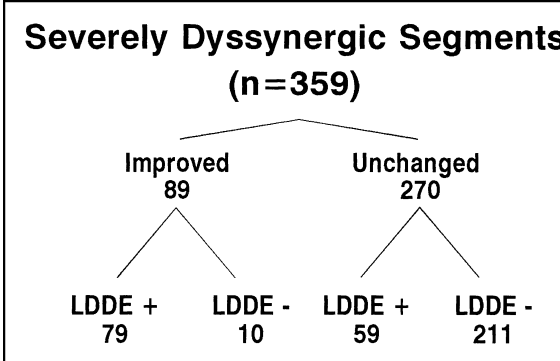

Mildly Dyssynergic Segments

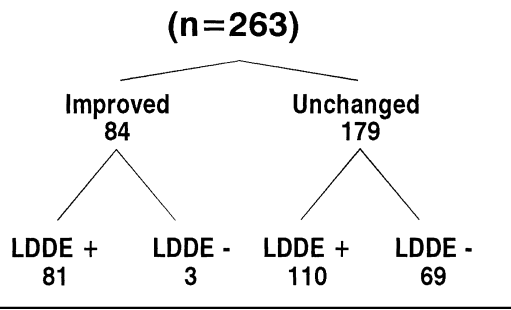

FIGURE 1. Flow chart showing the presence/absence of contractile reserve and functional outcome after revascularization in segments with severe (top) and mild (bottom) wall motion abnormalities. LDDE = low-dose dobutamine echocardiography.

sion of low-dose dobutamine improved by at least 1 point of the scoring system, with the exception of dyskinesia becoming akinesia. To compare the diagnostic accuracy of low-dose dobutamine echocardiography in mildly dyssynergic segments versus severely dyssynergic segments, the segments were divided into 2 groups: group I consisted of the mildly hypokinetic segments and group II consisted of the severely hypokinetic, akinetic, and dyskinetic segments.

To assess recovery of function, resting 2-dimensional echocardiograms were obtained in all revascularized patients before and 3 months after cardiac revascularization. Follow-up echocardiograms were compared with the corresponding resting images before revascularization, without knowledge of the dobutamine studies. For each segment, recovery of function was defined as an improvement of $\geq 1$ grade, again with the exception of dyskinesia becoming akinesia. We have previously reported a high inter- and intraobserver agreement for classification of resting wall motion (agreement $84 \%$ and $87 \%$ ) and response to low-dose dobutamine (agreement $92 \%$ and 94\%) in a comparable patient group. ${ }^{5}$

Data are presented as mean \pm SD. Univariate analysis for categorical variables was performed using the chi-square test with Yates' correction. Sensitivity and specificity figures and diagnostic accuracies were based on their standard definitions and are presented with corresponding 95\% confidence intervals. Differences in sensitivities and specificities between severely dyssynergic and mildly dyssynergic segments were determined by the McNemar test. A p value $<0.05$ was considered statistically significant.

Six hundred forty-three segments $(44 \%)$ showed 


\begin{tabular}{|c|c|c|c|c|c|c|}
\hline & Sens. (\%) & $95 \% \mathrm{Cl}$ & Spec. (\%) & $95 \% \mathrm{Cl}$ & DA (\%) & $95 \% \mathrm{Cl}$ \\
\hline Entire group & 92 & $80-100$ & 62 & $57-67$ & 66 & $63-69$ \\
\hline Mild dyssynergy & 96 & $92-100$ & 39 * & $32-46$ & $57^{*}$ & $51-63$ \\
\hline Severe dyssynergy & 89 & $82-96$ & 78 & $73-83$ & 81 & $77-85$ \\
\hline
\end{tabular}

racy in segments with mild dyssynergy. 9,10 In the current study we compared the accuracy in segments with severe and mild dyssynergy. Sensitivity was high for both categories. Specificity was high in segments with severe dyssynergy, but was significantly lower in segments with mild dyssynergy, indicating overestimation of recovery in these segments. This finding has important implications since currently all "vi-

abnormal wall motion. Of these segments, 21 were excluded because of inadequate revascularization (based on review of the surgery/angioplasty reports), leaving 622 for the final analysis; 263 segments (42\%) showed mild dyssynergy (group I) and 359 (58\%) segments showed severe dyssynergy (group II). The severely dyssynergic segments were supplied by more stenotic vessels (140 segments by a total occluded artery, 165 by a vessel with $>70 \%$ stenosis, and 54 by vessels with a $50 \%$ to $70 \%$ stenosis) than the mildly dyssynergic segments (33 by a total occluded artery, 117 by a $>70 \%$ stenosis, and 113 by a $50 \%$ to $70 \%$ stenosis).

After revascularization 173 segments (28\%) improved in function, $413(66 \%)$ remained unchanged, and $36(6 \%)$ deteriorated. Of the 263 group I segments, $84(32 \%)$ showed recovery of function, 158 $(60 \%)$ remained unchanged, and $21(8 \%)$ deteriorated. Of the 359 group II segments, 89 (25\%) showed recovery of function (including 46 severely hypokinetic, 41 akinetic, and 2 dyskinetic segments). Recovery of function occurred significantly more often in group I than in group II $(32 \%$ vs $25 \%, \mathrm{p}<0.05)$.

During low-dose dobutamine, a contractile reserve was elicited in 329 segments (53\%), whereas 293 segments $(47 \%)$ did not improve during the infusion of low-dose dobutamine. In particular, 191 group I segments $(73 \%)$ and 138 group II segments $(38 \%)$ (including 59 severely hypokinetic and 79 akinetic) exhibited a contractile reserve. Group I segments showed improvement significantly more often during dobutamine: $73 \%$ versus $38 \%$ ( $\mathrm{p}<0.05$, Figure 1 ). Sensitivities were comparable in groups I and II (96\% vs $89 \%)$. The specificity was significantly lower in group I (39\% vs $78 \%$, p <0.05, Table II). Similarly, the diagnostic accuracy was lower in group I (57\% vs $81 \%$, p <0.05). Sensitivities in mildly hypokinetic segments were comparable between patients with and without $\mathrm{Q}$ waves on the electrocardiogram. Although the specificity in mildly hypokinetic segments was lower in patients without $\mathrm{Q}$ waves (compared to patients with a $\mathrm{Q}$ wave), these values were not significantly different $(29 \%, 95 \%$ confidence interval $19 \%$ to $39 \%$ vs $48 \%$, $95 \%$ confidence interval $38 \%$ to $58 \%$ ).

$$
\text { -.. }
$$

Dobutamine echocardiography allows assessment of myocardial viability and prediction of functional recovery after revascularization..$^{4-11}$ In severely dyssynergic myocardium, the diagnostic accuracy of the test is high, but recent reports suggest a lower accu- ability" studies use recovery of function as the gold standard for myocardial viability, thus suggesting that low-dose dobutamine echocardiography may not be useful in mildly hypokinetic segments. The low specificity of low-dose dobutamine echocardiography in these segments may be attributed to the following phenomena:

1. Many hypokinetic segments may represent a mixture of subendocardial scar and normal myocardium. ${ }^{13}$ During dobutamine stimulation, the normal myocardium may become hyperkinetic (while the subendocardial infarct zone remains akinetic), resulting in apparent normokinesia. These segments will not recover function after revascularization. This hypothesis emphasizes the need for the distinction between the terms viability and recovery of function, as suggested in 2 recent editorials. ${ }^{14,15}$ On the other hand, when hypokinesia is caused by the presence of hibernating myocardium, recovery of function may occur after revascularization. Newer techniques with enhanced resolution, enabling us to differentiate between endocardial and epicardial wall motion, may overcome these shortcomings and improve specificity of lowdose dobutamine echocardiography. The fact that specificity tended to be lower in patients with a nonQ-wave infarction further substantiates the idea that many hypokinetic segments did contain subendocardial scar tissue. Moreover, the hypokinetic segments were subtended by less severe stenoses, also arguing in favor of subendocardial scar in these segments.

2. Tethering by adjacent akinetic segments may have caused irreversible hypokinesia. Recent studies have shown that the "biphasic response" to dobutamine may be more accurate in predicting functional recovery. ${ }^{11,16}$ This biphasic response to dobutamine is likely to be caused by the presence of a severe (critical) stenosis supplying the dyssynergic segment; after the initial recruitment of contractility, the stenosis becomes flow limiting at higher dosages of dobutamine, resulting in ischemia, reflected by worsening of wall motion. ${ }^{14,17}$ The combination of low- and high-dose dobutamine may be able to discriminate between subendocardial scar and hibernating myocardium.

Finally, all studies have used recovery of function as the end point in viability studies. Kaul, however, has recently pointed out that relief of ischemia, or the prevention of remodeling may clinically be more important end points than functional recovery. ${ }^{14,17}$ It can be hypothesized that the presence of subendocardial 
scar (and thus viability of the remaining myocardium) may be important in preventing left ventricular remodeling and long-term prognosis. ${ }^{18}$

In conclusion, these data further substantiate the hypothesis that low-dose dobutamine echocardiography has a relatively low specificity in segments with mild dyssynergy. This phenomenon can, at least in part, be attributed to the presence of subendocardial scar.

1. Rahimtoola SH. The hibernating myocardium. Am Heart J 1989;117:211-221. 2. Vanoverschelde JLJ, Wijns W, Depré C, Essamri B, Heyndrickx GR, Borgers M, Bol A, Melin JA. Mechanisms of chronic regional postischemic dysfunction in humans. New insights from the study of noninfarcted collateral-dependent myocardium. Circulation 1993;87:1513-1523.

3. Cornel JH, Bax JJ, Fioretti PM. Assessment of myocardial viability by dobutamine stress echocardiography. Curr Opin Cardiol 1996;11:621-626.

4. Baer FM, Voth E, Deutsch HJ, Schneider CA, Schicha H, Sechtem U. Assessment of viable myocardium by dobutamine transesophageal echocardiography and comparison with fluorine-18 fluorodeoxyglucose PET. J Am Coll Cardiol 1994;24:343-353.

5. Arnese M, Cornel JH, Salustri A, Maat APWM, Elhendy A, Reijs AEM, Ten Cate FJ, Keane D, Balk AHMM, Roelandt JRTC, Fioretti PM. Prediction of improvement of regional left ventricular function after surgical revascularization: a comparison of low-dose dobutamine echocardiography with 201-TL SPECT. Circulation 1995:91:2748-2752.

6. La Canna G, Alfieri O, Giubbini R, Gargano M, Ferrari R, Visioli O. Echocardiography during infusion of dobutamine for identification of reversible dysfunction in patients with chronic coronary artery disease. J Am Coll Cardiol 1994;23:617-626.

7. Baer FM, Voth E, Deutsch HJ, Schneider CA, Horst M, de Vivie ER, Schicha H, Erdmann E, Sechtem U. Predictive value of low dose dobutamine transesophageal echocardiography and fluorine-18 fluorodeoxyglucose positron emission tomography for recovery of regional left ventricular function after successful revascularization. J Am Coll Cardiol 1996;28:60-69.
8. Perrone-Filardi P, Pace L, Prastaro M, Piscione F, Betocchi S, Squame F, Vezzuto P, Soricelli A, Indolfi C, Salvatore M, Chiariello M. Dobutamine echocardiography predicts improvement of hypoperfused dysfunctional myocardium after revascularization in patients with coronary artery disease. Circulation 1995;91:2556-2565.

9. DeFilippi CR, Willett DWL, Irani WN, Eichhorn EJ, Velasco CE, Grayburn PA. Comparison of myocardial contrast echocardiography and low-dose dobutamine stress echocardiography in predicting recovery of left ventricular function after coronary revascularization in chronic ischemic heart disease. Circulation 1995;92:2863-2868.

10. Vanoverschelde J-LJ, D'Hondt A-M, Marwick T, Gerber BL, De Kock M, Dion R, Wijns W, Melin JA. Head-to-head comparison of exercise-redistributionreinjection thallium single-photon emission computed tomography and low dose dobutamine echocardiography for prediction of reversibility of chronic left ventricular ischemic dysfunction. J Am Coll Cardiol 1996;28:432-442.

11. Qureshi U, Nagueh SF, Afridi I, Vaduganathan P, Blaustein A, Verani MS, Winters WL, Zoghbi WA. Dobutamine echocardiography and quantitative restredistribution ${ }^{201} \mathrm{~T} 1$ tomography in myocardial hibernation. Relation of contractile reserve to ${ }^{201} \mathrm{~T} 1$ uptake and comparative prediction of recovery of function. Circulation 1997;95:626-635.

12. Pigott JD, Kouchoukos NT, Oberman A, Cutter GR. Late results of surgical and medical therapy for patients with coronary artery disease and depressed left ventricular function. J Am Coll Cardiol 1985;5:1036-1045.

13. Lieberman AN, Weiss JL, Jugdutt JL, Becker LC, Bulkley BH, Garrison JG, Hutchins GM, Kallman CA, Weisfeldt ML. Two-dimensional echocardiography and infarct size: Relationship of regional wall motion and thinning to the extent of myocardial infarction in the dog. Circulation 1981;63:739-746.

14. Armstrong WF. "Hibernating', myocardium: asleep or part dead? J Am Coll Cardiol 1996;28:530-535.

15. Kaul S. There may be more to myocardial viability than meets the eye! [editorial]. Circulation 1995;92:2790-2793.

16. Afridi I, Kleiman NS, Raizner AE, Zoghbi WA. Dobutamine echocardiography in myocardial hibernation. Optimal dose and accuracy in predicting recovery of ventricular function after coronary angioplasty. Circulation 1995;91:663670.

17. Kaul S. Response of dysfunctional myocardium to dobutamine. "The eyes see what the mind knows!'” [editorial]. J Am Coll Cardiol 1996;27:1608-1611. 18. Gaudron P, Eilles C, Kugler I, Ertl G. Progressive left ventricular dysfunction and remodeling after myocardial infarction: potential mechanisms and early predictors. Circulation 1993;21:683-691. AQ1-Give location (city and state or city and country if in Europe) of all manufacturers.

\title{
Insulin Resistance in Patients With Familial Combined Hyperlipidemia and Coronary Artery Disease
}

\author{
Juan F. Ascaso, MD, PhD, Rosario Lorente, MD, Angel Merchante, MD, José T. Real, MD, \\ Antonia Priego, MD, and Rafael Carmena MD, PhD
}

$\boldsymbol{F}$ amilial combined hyperlipidemia $(\mathrm{FCH})$ is an alteration in the metabolism of lipoproteins initially described in a study of family members of young survivors of myocardial infarction. ${ }^{1}$ The etiology of $\mathrm{FCH}$ is unknown because the phenotype is variable and the expression of the disease is affected by genetic, metabolic, and environmental factors. ${ }^{2} \mathrm{FCH}$ has a prevalence in the general population of $0.5 \%$ to $2 \%$ and between $15 \%$ and $20 \%$ in subjects with premature cardiovascular disease. ${ }^{3}$ The common factor in subjects with FCH is the increase in low-density lipoprotein (LDL) or very low density lipoprotein (VLDL), or both, with elevations in the apolipoprotein B levels and, frequently, low levels of high-density lipoprotein (HDL), abnormal composition of lipoproteins, central

\footnotetext{
From the Service of Endocrinology and Nutrition, Hospital Clinico, University of Valencia, Valencia, Spain. Dr. Ascaso's address is: Departament de Medicina, Universitat de Valencia, Avenida Blasco Ibañez 15, 46010 Valencia, Spain. Manuscript received June 12, 1997; revised manuscript received and accepted September 8, 1997
}

trunk obesity, hyperinsulinemia, and abnormal glucose tolerance. 4,5 These associations highlight the considerable metabolic heterogeneity of the FCH condition and arteriosclerosis. ${ }^{6}$ In the present study we have investigated insulin resistance (quantified using the minimal model of glucose metabolism modified by the administration of insulin) and other known cardiovascular disease risk factors in patients with $\mathrm{FCH}$ subgrouped according to the presence or absence of ischemic heart disease (IHD).

Patients (33 men) were diagnosed as having FCH after clinical and biochemical assessments of the probands and first-degree relatives. All patients selected were nonsmokers or ex-smokers for at least 1 year. Diagnosis was based on: the presence of hyperlipidemia of variable phenotypes IIa, IIb, or IV in firstdegree relatives of $\geq 2$ generations, family history of premature arteriosclerosis, elevated concentrations of apoprotein B in plasma $(>1.20 \mathrm{~g} / \mathrm{L})$, and absence of xanthomas in the proband and in first-degree relatives. The lipoprotein phenotypes were as described by 